\title{
Work schedules and fatigue: a prospective cohort study
}

\author{
N W H Jansen, L G P M van Amelsvoort, T S Kristensen, P A van den Brandt, IJ Kant
}

Occup Environ Med 2003;60(Suppl I):i47-i53

See end of article for authors' affiliations

......................

Correspondence to: N W H Jansen, Department of Epidemiology, Maastricht University, PO Box 616, 6200 MD Maastricht,

Netherlands;

Nicole.Jansen@

epid.unimaas.nl

Accepted

11 October 2002

\begin{abstract}
Aims: (1) To describe the prevalence of fatigue among employees in different work schedules (day work, three-shift, five-shift, and irregular shift work); (2) to investigate whether different work schedules are related to increasing fatigue over time, while taking into account job title and job characteristics; and (3) to study fatigue among shift workers changing to day work.

Methods: Data from nine consecutive four-monthly self administered questionnaires from the Maastricht Cohort Study on Fatigue at work $(n=12$ 095) were used with 32 months of follow up. Day and shift workers were matched on job title.

Results: The prevalence of fatigue was $18.1 \%$ in day workers, $28.6 \%$ in three-shift, $23.7 \%$ in five-shift, and $19.1 \%$ in irregular shift workers. For three-shift and five-shift workers substantial higher fatigue levels were observed compared to day workers at baseline measurement. In the course of fatigue over the 32 months of follow up there were only small and insignificant differences between employees in different work schedules. However, among employees fatigued at baseline, fatigue levels decreased faster over time among five-shift workers compared to fatigued day workers. Shift workers changing to day work reported substantially higher fatigue levels prior to change, compared to those remaining in shift work.

Conclusions: Substantial differences in fatigue existed between day and shift workers. However, as no considerable differences in the course of fatigue were found, these differences have probably developed within a limited time span after starting in a shift work job. Further, evidence was found that fatigue could be an important reason for quitting shift work and moving to day work. Finally, in the relation between work schedules and fatigue, perceived job characteristics might play an important role.
\end{abstract}

$\Delta$ lthough shift work has frequently been shown to have detrimental effects on the health of employees, it is becoming increasingly prevalent in contemporary life. ${ }^{12}$ Studies have shown that shift workers have an increased risk of cardiovascular disease, ${ }^{3-7}$ gastrointestinal disease, ${ }^{8-11}$ and reduced wellbeing. ${ }^{10}$ Shift work has also been associated with fatigue, ${ }^{212-14}$ and fatigue is frequently cited as a major cause of shift work intolerance. ${ }^{11}$ In many studies on shift work and fatigue, fatigue is defined and operationalised in different ways, for example in terms of increased sleepiness ${ }^{12}{ }^{15}$ and reduced alertness. ${ }^{16-18}$ In studies of scheduled long work shifts, performance decrements in both work related tasks and laboratory-type behavioural tests, significant sleep loss and increased subjective sleepiness have been reported. ${ }^{19}$ In our study, fatigue is seen as a subjective sensation with cognitive and behavioural components. Furthermore, we will only deal with fatigue persistent over a period of several days, also called prolonged fatigue. Prolonged fatigue is not easily reversible in the short term and is not task specific $^{20}$; furthermore, the compensating mechanisms that were useful in reducing acute fatigue are no longer effective. ${ }^{21}$ This prolonged fatigue, further referred to as fatigue, affects the individual's performance in the work and home setting and may lead to sick leave and work disability. ${ }^{22}$ Little is known however, about the course of fatigue over time among employees in different work schedules. More knowledge concerning the relation between work schedules and fatigue

Main messages

- Shift work is associated with a higher prevalence of fatigue, especially in three-shift work.

- Shift work could sustain higher fatigue levels over time.

- Fatigue could be an important reason for quitting shift work and moving to day work.

- In the relation between work schedules and fatigue, perceived job characteristics may play an important role. could have important consequences for employee health and implications for designing better shift systems.

Problems with shift work are most often attributed to the assumption that employees are being required to do the opposite of what their sleep-wake rhythm would predict-that is, to stay awake during the night and to sleep during the day. ${ }^{18}$ Since sleep is more efficient during the night and work is often more fatiguing during the night, ${ }^{23}$ considerable differences in the course and accumulation of fatigue between day and shift workers may exist. Van Veldhoven and Meijman, ${ }^{24}$ for example, found that working in shift systems required more effort and time to recover than working in day shifts. Further, important differences may also exist in the levels and course of fatigue among employees involved in different types of shift work. Working too many shifts in succession, having too short a period of rest in between two shifts, or having to sacrifice days off, can all have a strong negative impact on the opportunity to recover from fatigue at work ${ }^{25}$ and constitute characteristics of work schedules that often vary substantially between different shift work types. Fatigue might accumulate and build up over time, for example in work schedules with too short resting periods between the shifts, which do not allow employees to completely recover and thus cause fatigue levels to increase over time. For 12 hour shifts, for example, there seems to be a build up of fatigue over the period of work. ${ }^{26}$ Other work schedules may be related to accumulated fatigue as well. In three-shift work, for example, employees in general have only two weekend days available to recuperate and switch to a new shift cycle. Five-shift workers generally work fewer hours a week compared to three-shift workers, providing them with more opportunities to recover from

\section{Policy implication}

- In dealing with prevention and treatment of fatigue among employees, work schedules should be considered very seriously. 
fatigue at work. For irregular shift workers, the unpredictability in timing of work and rest periods could be specifically related to fatigue. Therefore, as reported by Rosa, ${ }^{27}$ fatigue experienced by employees will be a function of the number of hours worked, the timing of work in the 24 hour day (that is, what shift is worked), how many work shifts occur before a rest day, ${ }^{28}$ how many rest days are taken before return to work, how much rest is taken during the shift and between consecutive work shifts, and how variable the timing of the shift is.

Furthermore, fatigue is strongly influenced by other job characteristics, such as psychological job demands, decision latitude, and emotional and physical demands. ${ }^{29}$ Job characteristics often differ substantially between day and shift workers. ${ }^{30}$ Cross sectional analyses on the data of the Maastricht Cohort Study on Fatigue at Work revealed that the association between work schedules and need for recovery from work was also strongly influenced by other job characteristics, such as, for example, psychological job demands and physical demands. ${ }^{31}{ }^{32}$ Hence, as reported by Rosa, ${ }^{27}$ work schedules and workload factors need to be examined in combination to obtain a realistic picture of the effects of shift work on fatigue. Approaches to potential confounding with regard to shift work are to include measures of perceived job characteristics in the analysis of shift work effects ${ }^{33}$ and/or use occupation as a matching variable in the analyses. As work scheduling is superimposed on many other qualities of the workplace that may affect health and wellbeing, control subjects who are doing the same job, but on a different work schedule, are vital. ${ }^{34}$ In the present study job title will be used as a matching variable for comparing shift workers and day workers. In addition, adjustments will be made regarding perceived job characteristics. We hypothesised that shift work would be associated with a stronger accumulation of fatigue over time compared to day work. To elucidate whether work schedules actually go together with a different course of fatigue over time, prospective studies are a prerequisite. In this study we used 32 months of follow up data from the Maastricht Cohort Study on Fatigue at Work: (1) to describe the prevalence of fatigue among employees in different work schedules (three-shift work, five-shift work, irregular shift work, day work); (2) to investigate whether different work schedules are related to increasing fatigue levels over time, while taking into account job title and perceived job characteristics; and (3) to study fatigue among shift workers changing to day work during follow up.

\section{METHODS}

\section{Study population}

This study is part of the prospective Maastricht Cohort Study on Fatigue at Work, ${ }^{35}{ }^{36}$ in which employees from 45 different companies were followed by means of nine self administered questionnaires at four-monthly intervals. Once a year employees received an extensive questionnaire with items on work and non-work related factors, demographics, and health factors, as well as on fatigue. Twice a year employees received a short questionnaire, capturing mainly outcome measures. For the present study all nine consecutive questionnaires were used. In May 1998, a total of 26978 employees from 45 companies and organisations received a letter at home, inviting participation, and the self administered baseline questionnaire. A reminder was sent out after two weeks. After six weeks a brief non-response questionnaire was sent to a random subsample of 600 non-respondents. Non-response analyses yielded no significant differences between respondents and non-respondents regarding demographic characteristics. Non-respondents were somewhat less likely to report difficulties in work execution, fatigue complaints, and sick leave. Altogether, 12161 employees completed and returned the first questionnaire (response rate of $45 \%$ ). Sixty six questionnaires were excluded from analysis because of technical reasons or because inclusion criteria were not met.

The first measurement in May 1998 will further be referred to as the baseline. The baseline (T0) cohort consisted of 8840 (73\%) men and 3255 (27\%) women, aged 18-65 years. All employees who returned the baseline questionnaire (T0) also received the two short questionnaires Tl in September 1998 (response rate $87.6 \%, \mathrm{n}=10592$ ) and $\mathrm{T} 2$ in January 1999 (response rate $84.9 \%, \mathrm{n}=10270$ ). Employees who returned the baseline questionnaire and at least one of the short questionnaires ( $\mathrm{Tl}$ and/or $\mathrm{T} 2$ ) received the extensive questionnaire T3 in May 1999 (response rate 79.8\%, n = 9655). Employees returning the $\mathrm{T} 3$ questionnaire also received the short questionnaires T4 in September 1999 (response rate $74.0 \%$, $\mathrm{n}=8956$ ) and T5 in January 2000 (response rate 71.9\%, $\mathrm{n}=8692$ ). Employees who returned the questionnaire at T3 and at least one of the consecutive short questionnaires (T4 and/or T5) also received the extensive questionnaire T6 in May 2000 (response rate $66.7 \%, \mathrm{n}=8070$ ). Employees returning the T6 questionnaire also received the short questionnaire T7 in September (response rate 63.3\%, $\mathrm{n}=7662$ ) and the final T8 questionnaire in January 2001 (response rate $61.9 \%$, $\mathrm{n}=7482$ ).

Included in the present study were men and women, who worked three-shifts, five-shifts, irregular shifts, or who were involved exclusively in day work. We included only employees with a working week of at least 26 hours/week to establish more comparable working hours between day and shift workers. Temporary employees were excluded since they generally change jobs frequently. Further exclusion criteria were being absent from work at the time of completing the baseline questionnaire and not having completely resumed work after a period of sick leave at baseline. Also excluded were those employees with multiple jobs, since we had no information on working time arrangements and content of the other job.

The two questions "What is your job in the company/ organisation?" and "What is your most important task?" were used to assess an employee's job title in the current job. The responses to these open ended questions were used by trained coders to assign a job title, with a five digit code, based on The Netherlands Standard Classification of Occupations 1992. ${ }^{37}$ From the employees, 88 did not indicate their function or most important task. These employees were excluded from further analyses. At first measurement in May 1998, our study population captured 687 different job titles. ${ }^{38}$ Job title was used to match the employees in the different work schedule groupsthat is, for example, for employees working three-shift systems, a reference group of day workers with similar job title was matched. The minimum number of employees within one job title was two employees per shift type.

Employees reporting to have switched to another work schedule at any point during the 32 months follow up were excluded from the multilevel analyses $(n=68$ for day workers, $\mathrm{n}=158$ for three-shift workers, $\mathrm{n}=181$ for fiveshift workers, and $\mathrm{n}=96$ for irregular shift workers). With regard to the shift workers who changed to day work explicitly, however, separate subanalyses were performed concerning demographics and fatigue.

For the comparison of three-shift workers with day workers, 34 job titles were identified ( $\mathrm{n}=494$ for three-shift workers, $\mathrm{n}=675$ for day workers). Examples of job titles both in day work and three-shift work were production planner, operator, and assembler of vehicles. For comparing five-shift workers and matched day workers, 47 job titles were identified ( $n=663$ for five-shift workers, $n=1284$ for day workers). Examples of job titles both in day work and five-shift work were machine operator, maintenance electrician, and controller or tester electric machinery. Regarding irregular shift workers and matched day workers, 19 job titles were identified ( $n=161$ for irregular shift workers, $n=206$ for day workers ), 


\begin{tabular}{|l|c|c|c|c|c|c|c|}
\hline \multicolumn{7}{|c|}{ Three-shift work } \\
\hline Week & Mo & Tu & We & Th & Fr & Sa & Su \\
\hline 1 & M & M & M & M & M & - & - \\
\hline 2 & N & N & N & N & N & - & - \\
\hline 3 & E & E & E & E & E & - & - \\
\hline & Five-shift work & \multicolumn{5}{|l|}{} \\
\hline Week & Mo & Tu & We & Th & Fr & Sa & Su \\
\hline 1 & - & - & M & M & M & - & - \\
\hline 2 & N & N & N & N & - & - & - \\
\hline 3 & E & E & E & - & - & M & M \\
\hline 4 & M & M & - & - & N & N & N \\
\hline 5 & - & - & - & E & E & E & E \\
\hline
\end{tabular}

Figure 1 Examples of schedules in three-shift and five-shift work. $M$, morning shiff; $N$, night shiff; $E$, evening shift; -, day off.

for example mailman, enrolled nurse, and daycare worker/care taker of the elderly or mentally handicapped.

\section{Measures \\ Work schedules}

The questionnaire included 32 questions on working time arrangements, which enabled us to exactly select the work schedules employees were engaged in. A check among a sample of the cohort yielded that the information given by the employees corresponded with the company records on work schedules. In our study the term shift work is used for a work schedule, which includes night work. In the present study only day work, three-shift, five-shift, or irregular shift workers were included for investigating differences between the schedules. The direction of the shifts (clockwise, counterclockwise) varied between the companies. Figure l presents examples of a shift schedule for a team in three-shift as well as for a team in five-shift work. In the present study three-shift work, also referred to as $3 \times 8$ semicontinuous shift work, involves a 24 hour production from Monday to Friday carried out by three teams of employees, generally working eight hour shifts. In three-shift work, teams are switched as a rule every week. Five-day shift work involves full continuous shift work, spread over seven days including five alternating teams, generally working eight hour shifts. Only employees with a working week of at least 26 hours/week were selected to establish more comparable working hours between day and shift workers. Concerning actual working hours per week, the vast majority of five-shift workers worked 26-35 hours a week, whereas three-shift work generally comprised 36-40 hours a week. Employees working irregular shifts are involved in frequently deviating work hours, which can vary substantially every week, in the present study with a range from at least 26 hours to over 40 hours per week. For irregular shifts we included only those employees reporting frequent night work within their shift. The vast majority of day workers averaged 36-40 hours a week, with a range of 26 hours to over 40 hours per week.

\section{Fatigue}

The Checklist Individual Strength (CIS) was used to measure fatigue. ${ }^{39}{ }^{40}$ The CIS is a 20 item questionnaire developed to measure several aspects of fatigue, asking employees how they felt during the past two weeks. The CIS is a self report instru- ment consisting of four components, identified through factor analyse $^{39}$ : subjective experience of fatigue (eight items), concentration (five items), motivation (four items), and physical activity level (three items). The Cronbach's alpha of the total scale is 0.93 . CIS items are scored on seven point Likert scales. Higher scores indicate a higher degree of fatigue, more concentration problems, reduced motivation, or less activity. A composite CIS total score, ranging from 20 to 140 , is constructed by adding the individual's scores on the four factors in order to capture both the subjective sensation of fatigue as well as the reduction in functioning in terms of reduced concentration, motivation, and activity level. Missing data were treated on an individual level. Missing data on the subscales "subjective fatigue" (two of eight items missing at most), "motivation" (one of four items missing at most), and "concentration" (one of five items missing at most) of the CIS questionnaires were replaced with the means of the specific scale. CIS questionnaires containing more than four missing items were excluded from analysis. For case classification a cut off point of CIS total $>76$ was used, with all those scoring $>76$ designated as probable fatigue cases. This cut off was established in a separate pilot study by means of defined samples with differences in fatigue level. ${ }^{41}$

\section{Work environment}

Decision latitude was assessed with the Dutch version of the Job Content Questionnaire using the scale Decision Latitude (Cronbach's alpha 0.81), consisting of the two subscales Decision Authority and Skill Discretion. ${ }^{42}{ }^{43}$ To determine the level of psychological job demands the Dutch version of the Psychological Job Demands scale of the Job Content Questionnaire $^{42}{ }^{43}$ was used (Cronbach's alpha 0.69). The experience of physically demanding work was rated using an item of the Dutch questionnaire on Work and Health (VAG) ${ }^{44}$ The level of emotionally demanding work was assessed using a five item scale (Cronbach's alpha 0.60) consisting of two items of the Questionnaire on the Experience and Assessment of Work (VBBA), ${ }^{24}$ two items of the Questionnaire on Work and Health (VAG), ${ }^{44}$ and one self formulated item.

\section{Demographic and health factors}

Information on age, gender, educational level, employment history, and the presence of a long term disease was obtained through self report in the baseline questionnaire. Data on employment history in the present work schedule were completely available for shift workers only.

\section{Statistical analysis}

Each type of shift work (three-shift, five-shift, and irregular shift work) was compared with a reference group of day workers in similar job titles. We conducted multilevel analysis of a three level structure, with repeated measurements over time (level 1), in which the individual employees (level 2) were nested within job titles (level 3 ) by using SAS proc mixed models. To take into account the possibility that the course of fatigue may be different in different occupations we entered the interaction variable job title $\times$ time in every analysis. These multilevel analyses were able to control for selective dropouts. A confirmation that our model was robust was established by investigating whether leaving out specific jobs influenced the results, in which no significant changes appeared. In a first step the calculated betas were adjusted for age, gender, and the presence of a long term disease. In a second step, the betas were additionally adjusted for psychological job demands, decision latitude, and emotional and physical demands, which in separate analyses were shown to contribute independently to a significant change of the model. Additionally independent samples $t$ tests and $\chi^{2}$ tests were used to test univariate differences between the employees in different types of shift work 
Table 1 Descriptive characteristics of the study population

\begin{tabular}{|c|c|c|c|c|}
\hline & Day workł & Three-shift & Five-shift & Irregular shift \\
\hline $\mathrm{n}$ (number of organisations) & $4582(45)$ & 729 (17) & $930(10)$ & $321(24)$ \\
\hline Gender \% female & 21.9 & $8.8 * * *$ & $5.3 * * *$ & $30.5^{* * *}$ \\
\hline Age mean (SD) & $42.56(8.88)$ & $35.77^{* * *}(8.59)$ & $37.94 * * *(8.59)$ & $37.90 * * *(8.72)$ \\
\hline \multicolumn{2}{|l|}{ Highest educational level \% } & $* * *$ & $* * *$ & $* * *$ \\
\hline Primary school & 2.1 & 9.5 & 7.6 & 5.2 \\
\hline Lower vocational & 7.4 & 40.7 & 30.0 & 26.2 \\
\hline Lower secondary & 10.5 & 14.3 & 16.5 & 21.4 \\
\hline Intermediate vocational & 19.3 & 26.2 & 33.8 & 33.0 \\
\hline Secondary & 11.1 & 4.9 & 5.6 & 4.9 \\
\hline Higher vocational & 32.6 & 4.2 & 5.5 & 9.1 \\
\hline University & 17.0 & 0.2 & 1.0 & 0.2 \\
\hline \multicolumn{5}{|l|}{ Employment history§ } \\
\hline$\leqslant 5 y$ & & 78.4 & 30.5 & 26.1 \\
\hline $6-10 y$ & & 5.3 & 23.3 & 17.6 \\
\hline $11-15 y$ & & 5.5 & 23.4 & 14.5 \\
\hline$>15 y$ & & 10.8 & 22.8 & 41.8 \\
\hline Physically demanding work \% & 9.0 & $48.5^{* * *}$ & $33.4 * * *$ & $73.3^{* * *}$ \\
\hline Psychological job demands (12-48)† (SD) & $32.87(5.46)$ & $34.42 * * *(6.13)$ & $32.15 * *(5.68)$ & $34.52 * * *(5.85)$ \\
\hline Decision latitude (24-96)† (SD) & $74.44(10.02)$ & $65.08 * * *(13.62)$ & $68.11 * * *(11.47)$ & $68.11 * * *(11.64)$ \\
\hline Emotional demands $(0-5) \dagger(S D)$ & $0.83(1.09)$ & $1.53 * * *(1.44)$ & $1.17 * * *(1.23)$ & $1.93 * * *(1.42)$ \\
\hline Long term disease $\%$ & 21.1 & 22.8 & 19.4 & 24.8 \\
\hline \multicolumn{5}{|l|}{ Fatigue } \\
\hline Mean (20-140)† (SD) & $54.87(21.84)$ & $62.13^{* * *}(23.63)$ & $58.35^{* * *}(23.72)$ & $55.46(22.11)$ \\
\hline Cases $\%(C I S$ total score $>76)$ & 18.1 & $28.6 * * *$ & $23.7 * * *$ & 19.1 \\
\hline \multicolumn{5}{|c|}{$\begin{array}{l}\text { Significant difference with day work: }{ }^{* *} p<0.01 ;{ }^{* *} p<0.001 \text {. } \\
\text { †Scale range. } \\
\ddagger \text { Reference group for all three types of shift work. } \\
\text { §Data available for shift workers only. }\end{array}$} \\
\hline
\end{tabular}

Table 2 Fatigue over time by work schedule

\begin{tabular}{|c|c|c|c|c|c|c|}
\hline & \multicolumn{2}{|c|}{ Three-shift work } & \multicolumn{2}{|c|}{ Five-shift work } & \multicolumn{2}{|c|}{ Irregular shift work } \\
\hline & $\beta+\dagger$ & $\beta \pi$ & $\beta+†$ & $\beta$ 的 & $\beta+†$ & $\beta \pi$ \\
\hline Baseline difference $\dagger$ & $7.83 * * *$ & 1.70 & $6.30 * * *$ & 2.27 & 4.60 & -2.39 \\
\hline Course of fatigue within day work $\ddagger$ & 0.06 & -0.01 & 0.71 & 0.87 & 1.48 & 1.43 \\
\hline Course of fatigue within shift work $\S$ & 0.11 & 0.17 & 0.46 & 0.64 & 1.42 & 1.49 \\
\hline
\end{tabular}

For every shift type the reference group consisted of day workers with comparable job titles.

$* * * \mathrm{p}<0.001$.

†Difference in CIS total score between day (0) versus shift work type (1) at baseline measurement (May 1998).

†Change of fatigue over time in day workers per four months.

$\S$ Change of fatigue over time in shift workers per four months.

††Adjusted for age, gender, and long term disease.

IAdditionally adjusted for psychological job demands, decision latitude, and emotional and physical demands.

versus day work. All procedures were performed using SPSS for Windows release 9.0.0. and SAS release 8.02.

\section{RESULTS}

Table 1 presents descriptive characteristics of the study population before matching on job title. The percentage of women involved in three- and five-shift work was significantly lower compared to day work, whereas the percentage of women was significantly higher in irregular shift work compared to day work. Shift workers were younger in age compared to day workers and had on average received a lower education. Data on employment history in the present schedule were available only for shift workers, revealing that most three-shift workers worked five years or less in the present work schedule, whereas the majority of irregular shift workers had been involved in shift work for more than 15 years. With regard to job characteristics substantial differences emerged between the employees in different work schedules. For example, the percentage of employees reporting their work to be physically demanding was significantly higher in all types of shift work compared to day work. The prevalence of employees reporting a long term disease did not differ significantly between the work schedules. Compared to day work, the prevalence of fatigue was substantially higher in most shift work groups, with three-shift workers reporting the highest prevalence $(28.6 \%)$.

Since substantial differences existed in the work related factors between day and shift workers (table 1), we matched the day and shift workers on job title in all further analyses. Table 2 presents the results of the multilevel analyses for fatigue by work schedule. As table 2 shows, at baseline measurement in May 1998, the CIS total score of three-shift workers was 7.83 points higher compared to day workers, when controlled for age, gender, and the presence of a long term disease. Furthermore, for five-shift workers a significant difference with day workers in CIS total score (6.30 points) was observed at first measurement. Regarding irregular shift work, only non-significant results were obtained, with smaller differences in fatigue levels between day and irregular shift workers at baseline.

The variable "course of fatigue within day work" represents the estimated average change in CIS total score among day workers every four months over the total observation period of 32 months. The CIS total score increased over time but this increase was not statistically significant. As for every type of shift work different occupation matched day workers were selected, insignificant differences in betas between the day 
Table 3 Course of fatigue by work schedule among employees fatigued at baseline

\begin{tabular}{|c|c|c|c|c|}
\hline & \multicolumn{2}{|c|}{ Three-shift work } & \multicolumn{2}{|c|}{ Five-shift work } \\
\hline & $\beta+\dagger$ & $\beta \pi$ & $\beta+\dagger$ & $\beta \pi$ \\
\hline $\begin{array}{l}\text { Baseline difference } \dagger \\
\text { Course of fatigue within day work } \ddagger \\
\text { Course of fatigue within shift work§ }\end{array}$ & $\begin{array}{r}3.75 \\
-0.13 \\
0.16\end{array}$ & $\begin{array}{r}1.78 \\
-0.17 \\
0.21\end{array}$ & $\begin{array}{l}7.14 \\
0.03 \\
-2.07^{*}\end{array}$ & $\begin{array}{l}5.23 \\
-0.02 \\
-2.11 *\end{array}$ \\
\hline \multicolumn{5}{|c|}{ 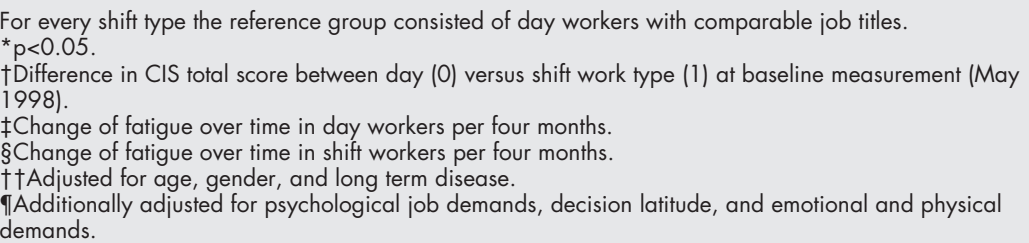 } \\
\hline
\end{tabular}

workers can be observed. The variable "course of fatigue within shift work" indicates the estimated average change in CIS total score among the different types of shift workers per four months over the total observation period of 32 months. The CIS total scores for all types of shift workers increased as well, but this increase in fatigue over time in shift workers was not significantly higher compared to day workers. In a second step the betas were additionally adjusted for several job characteristics, resulting in a substantial decrease of the difference in fatigue score between the day and shift workers at baseline measurement, in which all distinguished job characteristics contributed significantly.

The course of fatigue might be different in employees already designated as probable fatigue cases at baseline. Table 3 presents the results of the course of fatigue in different work schedules among employees designated as probable fatigue cases at baseline-that is, employees reporting a CIS total score of $>76$. The same criteria for matching on job title were applied as described in the Methods section, resulting for the comparison of three-shift workers with day workers in six job titles ( $\mathrm{n}=33$ for three-shift workers, $\mathrm{n}=41$ for day workers). For comparing five-shift workers and matched day workers, eight job titles were identified $(\mathrm{n}=6 \mathrm{l}$ for five-shift workers, $\mathrm{n}=45$ for day workers). The course of fatigue among fatigued employees working in irregular shifts could not be studied because of a too small sample size of the fatigued group. As table 3 shows, there were differences in the CIS total score between fatigued day and shift workers at baseline, although these were not statistically significant. The decrease in baseline difference of CIS total score between day and shift workers after controlling for perceived job characteristics was less pronounced compared to the differences in table 2. In three-shift workers, physical demands mainly contributed to the decrease of the beta "baseline difference". In contrast to fatigued day workers, the CIS total score in fatigued five-shift workers decreased significantly more over time after controlling for confounding factors.

A separate analysis was conducted to study the role of employment history in the relation between work schedules and fatigue. We were not able to compare the exposure time to shift work with the years spent in day work, because of missing data, especially in the day workers group. Therefore, we decided to study the role of job tenure within shift work specifically, in which the category of employees with over 15 years of shift work experience was treated as a reference group. These analyses could be conducted in five-shift work only, since only in five-shift work were all four distinguished categories well represented. We performed multilevel analyses, in which we compared fatigue levels in four categories of job tenure in five-shift work. Employees involved in five-shift work for $0-5$ years, $6-10$ years, or $11-15$ years were compared with workers with a job tenure of over 15 years in five-shift work. In these analyses only non-significant results were obtained, although there seemed to be a trend that the employees with the lowest job tenure (0-5 years in five-shift work) reported the highest fatigue levels at baseline.

As described in the Methods section, employees who switched from work schedule at any point during the 32 months of follow up were excluded from the multilevel analyses. We did, however, make a comparison between those shift workers (including three-shift workers, five-shift workers, and irregular shift workers) who changed explicitly to day work at one point during the follow up period $(n=150)$ and the shift workers remaining in the same work schedule ( $\mathrm{n}=444)$ during the total observation period. Only employees with complete data were included. Shift workers changing to day work generally received a somewhat higher education $(p<0.05)$ compared to those remaining in shift work. No significant differences were observed with respect to gender, age, and the presence of a long term disease. Regarding fatigue, on average six months prior to the change from shift to day work, shift workers scored 9.4 points higher on the CIS $(p<0.001)$ compared to those remaining in shift work. On average two months prior to this change, employees scored on average 6.7 points higher on the CIS $(\mathrm{p}<0.01)$ compared to those remaining in shift work. From just after the change until on average six months after the change to day work, employees reported no significant differences in fatigue levels compared to those remaining in shift work.

\section{DISCUSSION}

The present study found that fatigue was significantly more prevalent among three- and five-shift workers compared to day workers. At baseline substantial differences in fatigue existed among the employees in different work schedules, which significantly decreased after controlling for job characteristics. In the time course of fatigue there were only minor differences between employees in different work schedules. In fatigued employees, however, the level of fatigue decreased significantly faster over time among five-shift workers compared to day workers. Shift workers changing to day work reported significant higher fatigue levels prior to their change compared to those remaining in shift work.

A comparison of the observed prevalences of fatigue with other studies is difficult because most studies used different definitions and operationalisations of fatigue. Various studies have shown, however, that shift workers generally report more fatigue than day workers. ${ }^{12}{ }^{15}$ In a study by Rosa and colleagues, ${ }^{45}$ it was found that perceived muscular fatigue increased more quickly across the night shifts compared with day shifts. Accumulated fatigue across consecutive workdays was illustrated in a study by Schroeder and colleagues, ${ }^{46}$ where progressive increases in choice reaction time were apparent across a five day week of eight-hour shifts and a four day week of 10-hour shifts in air traffic control specialists. Åhsberg and 
colleagues $^{47}$ reported that fatigue, in terms of lack of energy and physical exertion, tended to accumulate during night shifts.

To our knowledge, this is the first study to examine the relation between various work schedules and the course of fatigue over a relatively long follow up period. Although fatigue did not significantly increase over time in neither shift nor day workers, shift work clearly sustained the higher levels of fatigue that already existed between day and shift workers. No indication of further accumulation of fatigue over time was found. The possibility exists that the effects of shift work on fatigue develop very quickly after starting to work in a shift work job, for which some indications were found when comparing fatigue levels in different categories of years of shift work experience among five-shift workers. As regards fatigue status, in employees fatigued at baseline, the fatigue levels over time decreased significantly faster in five-shift workers compared to day workers. Between fatigued day and three-shift workers no significant difference in change of fatigue over time was observed. It is possible that five-shift workers who were unable to cope with the fatigue accompanying their shift work have already left shift work. Compared to five-shift workers, three-shift workers generally were lower educated, which could make it more difficult for them to change jobs. In addition, compared to three-shift workers, five-shift workers have a working week comprising fewer hours, providing them with more opportunities to recover from their work and prevent fatigue from further accumulation. Three-shift workers generally only have two (weekend) days available to recuperate and switch to a new shift cycle. The traditional weekly change of shifts, as for example seen in three-shift work, is often reported to be the worst solution. ${ }^{2648}$

When studying the relation between work schedules and fatigue, the role of actual working hours in day work versus shift work has to be acknowledged. To reduce the potential confounding effect of working hours in the relation between work schedules and fatigue, we made a selection on working hours in this study - that is, we selected only those employees who reported to work at least 26 hours per week. For the comparison of day work and five-shift work, the day workers may be somewhat at a disadvantage with regard to working hours. Day workers could be somewhat more fatigued as a result of higher average working hours per week as compared to five-shift work, which may have resulted in an underestimation of the effects of five-shift work.

Besides time needed for recovery, sleep deficits could be an explanation for differences in fatigue levels between the day and shift workers in general. When there are several night shifts in a row there is likely to be a bigger cumulative sleep deficit towards the end of a span of night shifts, ${ }^{49}{ }^{50}$ whereas after a single night shift (or two night shifts) the sleep deficit can be compensated at once. ${ }^{48}$ Accumulated sleep debt could also constitute an explanation why shift work sustains higher fatigue levels among employees.

Although matching on job title was important for comparison of employees in different schedules but with similar job characteristics and educational level, the adjustment for job characteristics still decreased the association between work schedules and fatigue substantially. Apparently, compared to day workers, shift workers perceive these job characteristics, such as physical demands, as far more demanding, possibly since they are fighting their sleep, or that job demands in similar jobs actually are more demanding when performed in shift work compared to day work. Another possibility is that shift workers experienced their jobs as more demanding because they were more fatigued. We are aware that adjustment for job characteristics may therefore lead to overcontrol and thus could lead to underestimation of risks, since the self reported job characteristics may be associated with fatigue because of the problem of common method variance.
We therefore assume that the relatively crude results, only adjusted for age, gender, and long term disease, are more likely to represent the actual effect of shift work and reflect the differences in fatigue levels employees in different work schedules actually encounter. However, to disentangle possible mechanisms linking work schedules to fatigue over time, the analyses with adjustments for job characteristics provided important additional information. In the different groups of day workers the trends of fatigue over time varied, reflecting the fact that these groups of day workers were made up by employees with very different job titles and hence other job demands accompanying their work. This study dealt with work schedules, the role of perceived job characteristics, and the course of fatigue only. However, other factors could also be considered, such as individual characteristics, work-family conflict, and social pressures, which could influence the relation between work schedules and fatigue as well.

When interpreting the results of this study, several methodological issues should be considered. Since the Maastricht Cohort Study does not constitute a representative sample of the Dutch working population, the study population within the different work schedules does not reflect a representation of the employees involved in these work schedules in general and by matching on occupation any representativeness is even worse. However, studying the effects of different types of shift work does not require a representative sample, and as a broad range of occupations was still present we do consider the effects likely to be present in most shift work jobs. No misclassification of work schedules took place, since the questionnaire captured precise questions on working time arrangements, enabling us to specifically select the work schedules employees are involved in. Furthermore, the information in the questionnaire on work schedules was checked with the company records on work schedules. Another issue is that our study captured employees already involved in shift work for several years. The same is true for day workers. In this respect our first measurement is not a true baseline measurement. With regard to shift work, it is well known that different selection processes take place. ${ }^{6}$ Because of self selection and pre-job medical examinations, primary selection processes could have led to differences between the day and shift workers. ${ }^{51}$ With experienced shift workers we may have a self selected and robust group of employees who are either more able or more determined to adapt. ${ }^{34}$ Because of secondary selection processes and by excluding those employees who changed their work schedule at one point during our follow up an underestimation of the observed levels and course of fatigue over time may have resulted. The lower mean age and the larger dropout of the shift workers compared to the day workers clearly point in this direction. We did, however, have a unique opportunity to study whether fatigue could be a reason for quitting shift work and moving to day work. Indeed, compared to those remaining in shift work, employees who changed from shift to day work reported substantially higher fatigue levels on average six months prior to changing to day work. On average two months prior to changing to day work employees also scored higher on fatigue, although the fatigue levels were somewhat lower compared to six months prior to change. Possibly at this point, employees had already decided to change work schedules or had already found a future job in day work, resulting in lower fatigue levels because of the prospect of leaving their shift work job.

Although selection processes certainly played their part in this study, it did provide new insights on several aspects. The hypothesis that shift work is associated with a higher prevalence of fatigue certainly seems justified. Over time shift work seems to sustain the higher fatigue levels observed in shift workers compared to day workers. Fatigue is frequently cited as a major cause of shift work intolerance, ${ }^{11}$ and this study actually provided evidence that fatigue could be an important reason for quitting shift work. Furthermore, in the 
relation between work schedules and fatigue, perceived job characteristics may play an important role, which should also be considered in future studies on the effects of shift work. The present study aimed at the course of fatigue over time. We did not capture the onset and time span during which the large differences in fatigue levels between day and shift workers have developed. This time period has probably taken place before our baseline measurement, and has most likely occurred in the first time period after starting to work in a shift work job. Future studies on work schedules and fatigue should aim at this onset of the different levels in fatigue observed among employees involved in different work schedules, ideally requiring a cohort of employees starting to work in a shift work job.

\section{ACKNOWLEDGEMENTS}

The Maastricht Cohort Study is part of the Netherlands concerted research action on "Fatigue at work" granted by the Netherlands Organisation for Scientific Research. The present study was supported by grant no. 580-02.201 from the Netherlands Organisation for Scientific Research.

\section{Authors' affiliations}

N W H Jansen, L G P M van Amelsvoort, P A van den Brandt IJ Kant, Department of Epidemiology, Faculty of Medicine, Maastricht University, Maastricht, Netherlands

T S Kristensen, National Institute of Occupational Health, Copenhagen, Denmark

\section{REFERENCES}

1 Smith CS, Robie C, Folkard S, et al. A process model of shiftwork and health. J Occup Health Psychol 1999;4:207-18.

2 Härmä $M$. New work times are here-are we ready? Scand J Work Environ Health 1998;24(suppl 3):3-6.

3 Bøggild $\mathbf{H}$, Knutsson A. Shift work, risk factors and cardiovascular disease. Scand J Work Environ Health 1999:25:85-99.

4 Knutsson A, Åkerstedt T, Jonsson BG, et al. Increased risk of ischaemic heart disease in shift workers. Lancet 1986;ii:89-92.

5 Tenkanen L, Sjöblom T, Kalimo R, et al. Shift work, occupation and coronary heart disease over 6 years of follow-up in the Helsinki Heart Study. Scand J Work Environ Health 1997;23:257-65.

6 Kristensen TS. Cardiovascular diseases and the work environment. A critical review of the epidemiologic literature on nonchemical factors. Scand J Work Environ Health 1989;15:165-79.

7 Van Amelsvoort LPGM, Schouten EG, Maan AC, et al. Changes in frequency of premature complexes and heart rate variability related to shift work. Occup Environ Med 2001;58:678-81.

8 Tüchsen F, Jeppesen HJ, Bach E. Employment status, non-daytime work and gastric ulcer in men. Int J Epidemiol 1994;23:365-70.

9 Angersbach $D$, Knauth $P$, Loskant $H$, et al. A retrospective cohort study comparing complaints and diseases in day and shift workers. Int Arch Occup Environ Health 1980;45: 127-40.

10 Costa G. The impact of shift and night work on health. Appl Ergon 1996;27:9-16.

11 Harrington JM. Shift work and health. A critical review of the literature on working hours. Ann Acad Med Singap 1994:23:699-705.

12 Åkerstedt T. Sleepiness as a consequence of shift work. Sleep 1988;11:17-34

13 Smith L, Folkard S, Tucker P, et al. Work shift duration: a review comparing eight hour and 12 hour shift systems. Occup Environ Med 1998;55:217-29.

14 Ono Y, Watanabe S, Kaneko S, et al. Working hours and fatigue of Japanese flight attendants (FA). J Hum Ergol 1991;20: 155-64.

15 Åkerstedt T. Psychological and psychophysiological effects of shift work. Scand J Work Environ Health 1990;16(suppl 1):67-73.

16 Rosa RR. Performance, alertness, and sleep after 3.5 yrs of $12 \mathrm{~h}$ shifts: a follow-up study. Work Stress 1991;5:107-16.

17 Rosa RR. Performance and alertness on $8 \mathrm{~h}$ and $12 \mathrm{~h}$ rotating shifts at a natural gas utility. Ergonomics 1993;36:1 177-93.

18 Tucker P, Barton J, Folkard S. Comparison of eight and 12 hour shifts: impacts on health, wellbeing, and alertness during the shift. Occup Environ Med 1996;53:767-72.

19 Rosa RR. Extended workshifts and excessive fatigue. J Sleep Res 1995;4(suppl 2):51-6.

20 Meijman T, Schaufeli W. Psychische vermoeidheid en arbeid; Ontwikkelingen in de A\&O-psychologie [Mental fatigue and work. Developments in Work and Organizational Psychology]. Psycholoog 1996;31:236-41.
21 Meijman TF. Over vermoeidheid: arbeidspsychologische studies naar beleving van belastingseffecten. [Fatigue: studies on the perception of workload effects]. Amsterdam: University of Amsterdam, 1991.

22 Schröer CAP. De toename van arbeidsongeschiktheid wegens psychische aandoeningen [The increase of work disability due to mental disorders]. TBV 1997:5:16-23.

23 Vespa S, Wylie D, Mitler M, et al. Study of commercial vehicle driver rest periods and recovery of performance in an operational environment In: Hartley L, ed. Managing fatigue in transportation. Oxford: Pergamon, 1998: 119-65.

24 Van Veldhoven M, Meijman TF. Het meten van psychosociale arbeidsbelasting met een vragenlijst: de vragenlijst beleving en beoordeling van de arbeid (VBBA) [The measurement of psychosocial job demands with a questionnaire (VBBA)]. Amsterdam: NIA, 1994.

25 De Vries-Griever AHG. Evenwicht tussen werkdruk en herstel bij afwijkende werktijden. Uitgangspunten voor dienstroosterplanning [Balancing work load and recovery in deviating working hours. Basic principles of rota planning]. Groningen/Utrecht: Nationaal Ziekenhuisinstituut, 1992.

26 Knauth P. The design of shift systems. Ergonomics 1993;36:15-28.

27 Rosa RR. Examining work schedules for fatigue: it's not just hours of work. In: Hancock PA, Desmond PA, eds. Stress, workload and fatigue. Mahwah: Lawrence Erlbaum Associates, 2001:513-28.

28 Smith L, Macdonald I, Folkard S, et al. Industrial shift systems. Appl Ergon 1998;29:273-80.

29 Bültmann U, Kant IJ, Van den Brandt PA, et al. Psychosocial work characteristics as risk factors for the onset of fatigue and psychological distress: prospective results from the Maastricht Cohort Study. Psychol Med 2002;32:333-45

30 Bøggild H, Burr H, Tüchsen F, et al. Work environment of Danish shift and day workers. Scand J Work Environ Health 2001;27:97-105.

31 Jansen NW, Kant IJ. Need for recovery related to working time arrangements: results from the Maastricht Cohort Study on fatigue at work. Int J Behav Med 2000;7(suppl 3):S9.

32 Jansen NWH, Kant I, Nijhuis FJN, et al. Work schedules as risk factors for need for recovery and fatigue: results from the Maastricht Cohort Study after one year follow-up. Shiftwork International Newsletter 2001;18:52.

33 Parkes KR. Shiftwork, job type, and the work environment as joint predictors of health-related outcomes. J Occup Health Psychol 1999;4:256-68

34 Bohle P, Tilley AJ. The impact of night work on psychological well-being Ergonomics 1989;32:1089-99.

35 Kant IJ, Bültmann U, Schröer KAP, et al. An epidemiological approach to study fatigue in the working population: The Maastricht Cohort Study. Occup Environ Med. 2003;60:i32-9.

36 Kant IJ, Beurskens AJHM, Schröer CAP, et al. De Maastrichtse Cohort Studie naar langdurige psychische vermoeidheid in de arbeidssituatie [The Maastricht Cohort Study on fatigue at work]. TBV 2000;8:226-32.

37 Central Bureau of Statistics. Standaard Beroepenclassificatie 1992 [The Netherlands Standard Classification of Occupations 1992] 's-Gravenhage: SDU/vitgeverii, 1993

38 Bültmann U, Kant IJ, Van Amelsvoort LGPM, et al. Differences in fatigue and psychological distress across occupations: The Maastricht Cohort Study of Fatigue at Work. J Occup Environ Med 2001;43:976-83.

39 Vercoulen JH, Swanink CM, Fennis JF, et al. Dimensional assessment of chronic fatigue syndrome. J Psychosom Res 1994;38:383-92.

40 Beurskens AJ, Bültmann U, Kant IJ, et al. Fatigue among working people: validity of a questionnaire measure. Occup Environ Med 2000:57:353-7.

41 Bültmann U, De Vries M, Beurskens AJHM, et al. Measurement of prolonged fatigue at work in the Maastricht Cohort Study: Determination of a cutoff point. J Occup Health Psychol 2000;5:411-16.

42 Houtman I. Reliability and validity of the Dutch version of the Karasek Job Content Questionnaire. In: NIOSH/APA conference on Stress, Work and Health; Washington, DC: APA, 1995.

43 Karasek RA. The Job Content Questionnaire and User's Guide (version 1.1). Los Angeles: Department of Industrial and Systems Engineering, University of Southern California, 1985.

44 Gründemann RWM, Smulders PWG, De Winter CR. Handleiding Vragenlijst Arbeid en Gezondheid [Manual, Questionnaire on work and health]. Lisse: Swets \& Zeitlinger, 1993.

45 Rosa RR, Bonnet MH, Cole LL. Work schedule and task factors in upper-extremity fatigue. Hum Factors 1998;40:150-8.

46 Schroeder D, Rosa RR, Witt A. Some effects of 8-versus 10-hour work schedules on the test performance/alertness of air traffic control specialists. Int J Ind Ergonom 1998;21:307-21.

47 Åhsberg E, Kecklund G, Ảkerstedt T, et al. Shiftwork and differen dimensions of fatigue. Int J Ind Ergonom 2000;26:457-65

48 Knauth P. Designing better shift systems. Appl Ergon 1996;27:39-44.

49 Escriba V, Perez Hoyos S, Bolumar F. Shiftwork: its impact on the length and quality of sleep among nurses of the Valencian region in Spain. Int Arch Occup Environ Health 1992;64:125-9.

50 Foret J, Benoit $O$. Shiftwork: the level of adjustment to schedule reversal assessed by a sleep study. Waking Sleeping 1978;2:107-12.

51 Van Amelsvoort LPGM. Cardiovascular risk profile in shift workers. Cardiac control, biological and lifestyle risk factors [dissertation]. Wageningen: Wageningen University, 2000. 